\title{
Splenic macrophage subsets and their function during blood-borne infections
}

OPEN ACCESS

Edited by:

Ivan C. Moura,

INSERM, France

Reviewed by:

Martin Herrmann,

Universitätsklinikum Erlangen,

Germany

Takahiro Yamazaki,

Institute Gustave Roussy, France

${ }^{*}$ Correspondence: Henrique Borges da Silva and Maria Regina D'Império Lima, Department of Immunology, Instituto

de Ciências Biomédicas,

Universidade de São Paulo,

1730 - Room 226, 2nd Floor,

São Paulo 05508-000, Brazil

henrique.borges.silva@usp.br; relima@usp.br

tPresent address:

Henrique Borges da Silva, Department of Laboratory Medicine and Pathology, University of Minnesota, Minneapolis, MN, USA

¥Henrique Borges da Silva and Raíssa Fonseca have contributed equally to this work.

Specialty section:

This article was submitted to Molecular Innate Immunity, a section of the journal Frontiers in Immunology

Received: 30 June 2015 Accepted: 03 September 2015 Published: 22 September 2015

Citation:

Borges da Silva $H$, Fonseca $R$ Pereira RM, Cassado AA, Álvarez JM and D'Império Lima MR (2015)

Splenic macrophage subsets and their function during blood-borne infections.

Front. Immunol. 6:480. doi: 10.3389/fimmu.2015.00480

\author{
Henrique Borges da Silva ${ }^{\star \neq \neq}$, Raíssa Fonseca ${ }^{\ddagger}$, Rosana Moreira Pereira, \\ Alexandra dos Anjos Cassado, José Maria Álvarez and Maria Regina D’Império Lima*
}

Department of Immunology, Instituto de Ciências Biomédicas, Universidade de São Paulo, São Paulo, Brazil

The spleen is one of the major immunological sites for maintaining blood homeostasis. Previous studies showed that heterogeneous splenic macrophage populations contribute in complimentary ways to control blood-borne infections and induce effective immune responses. Marginal metallophilic macrophages (MMMФs) and marginal zone macrophages (MZM $\Phi$ s) are cells with great ability to internalize blood-borne pathogens such as virus or bacteria. Their localization adjacent to T- and B-cell-rich splenic areas favors the rapid contact between these macrophages and cells from adaptive immunity.

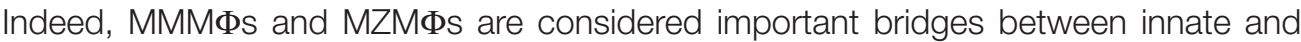
adaptive immunity. Although red pulp macrophages (RpM $\Phi$ s) are mainly considered scavengers for senescent erythrocytes, several data indicate a role for RpM $\Phi$ s in control of infections such as blood-stage malaria as well as in the induction of innate and adaptive immunity. Here, we review current data on how different macrophage subsets recognize and help eliminate blood-borne pathogens, and, in turn, how the inflammatory microenvironment in different phases of infection (acute, chronic, and after pathogen clearance) influences macrophage function and survival.

Keywords: spleen, macrophages, phagocytosis, pattern-recognition receptors, tissue remodeling

\section{Introduction}

Effective control of infections through the immune system is ensured by the well-organized structure of secondary lymphoid organs, which allow capture, processing, and presentation of antigens, ultimately leading to successful elimination of pathogens and induction of adaptive immunity. Among lymphoid organs, the spleen is particularly shaped for clearance of blood-borne pathogens. Microanatomically, the spleen is divided into the white pulp and the red pulp (Rp), separated by the marginal zone (MZ) [reviewed in Ref. (1)]. Rp and MZ have a complex macrophage (MФ) network with distinct origins and functions in the immune response to infections. RpMФs form a vast network inside the $\mathrm{Rp}$ and are characterized in mice by expression of $\mathrm{F} 4 / 80^{\text {high }} \mathrm{CD} 68^{+} \mathrm{CD} 1$ $1 b^{\text {low/ }-}$ and intense autofluorescence (2). In turn, inside the MZ, two populations of $M \Phi$ s can be discerned. The MZMФs typically express in their surface the C-type lectin SIGN-related 1 (SIGNR1) and a type I scavenger receptor called Macrophage Receptor with Collagenous structure (MARCO), which recognize non-opsonized molecules (3), mainly blood-borne antigens (4). Furthermore, marginal metallophilic $\mathrm{M} \Phi \mathrm{s}(\mathrm{MMM} \Phi \mathrm{s}$ ) are defined, among other molecules, by the expression of Sialic acid-binding Ig-like Lectin-1 (Siglec-1, Sialoadhesin, CD169) and MOMA-1 (5). A general scheme of the spleen structure is depicted in Figure 1. 


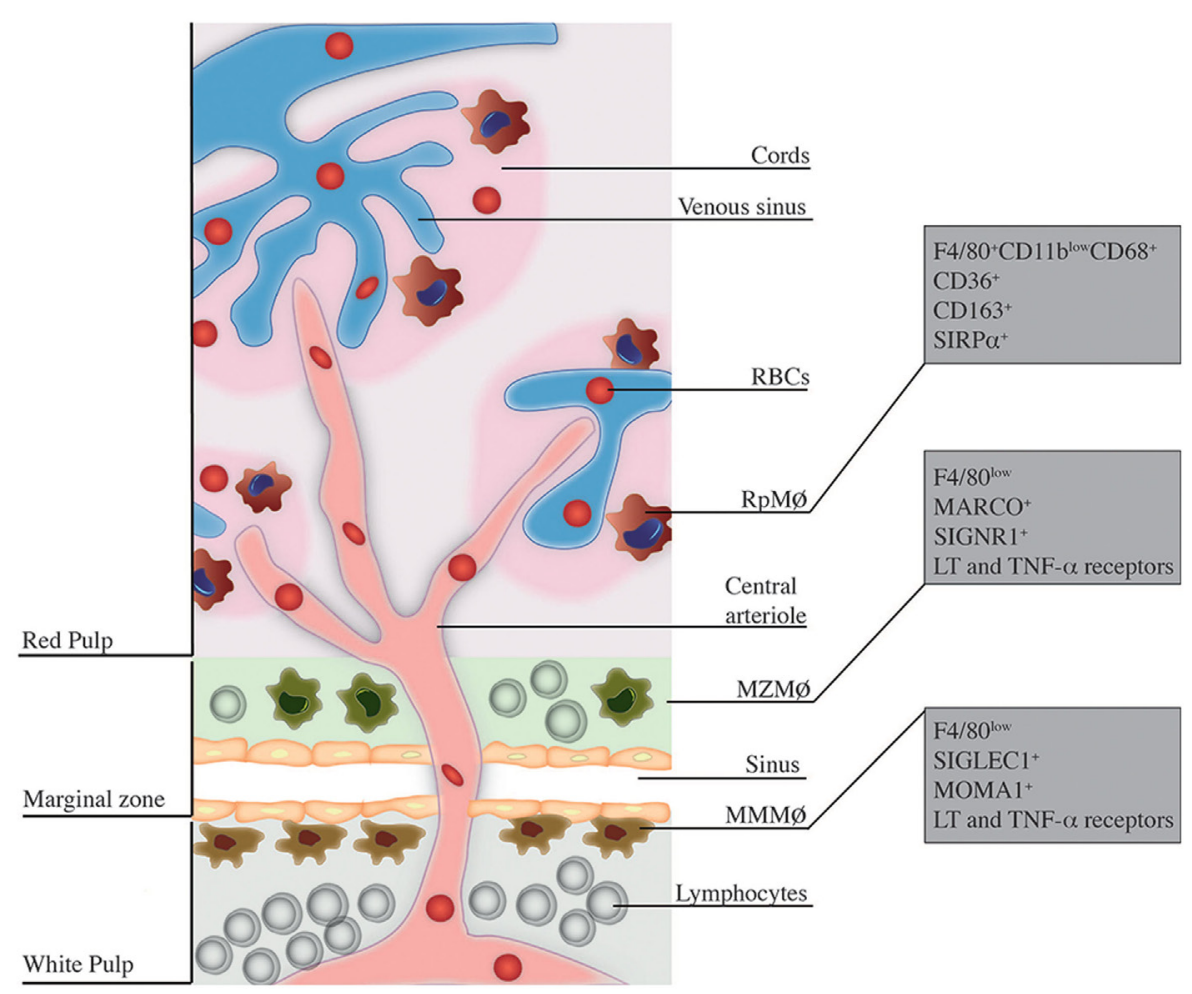

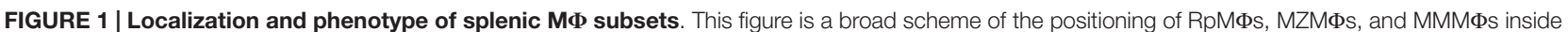
spleen and their respective phenotypic markers. RpM $\Phi$ s (in red) are typically found within cords on the red pulp, allowing direct contact with RBCs and other blood cells/particles passing through venous sinuses. They are better defined by the concomitant expression of F4/80, CD11b (at low levels), and CD68 as well as other receptors that aid in their function. MZMФs (in green) are found in the marginal zone (MZ) outer layer - they are also in direct contact with blood-borne particles. These cells express in their surface the molecules MARCO and SIGNR1 and other receptors that help in the uptake of blood-borne pathogens. Finally, the MMMФs (in brown) reside within the inner layer of the $\mathrm{MZ}$, in the contact with the white pulp. They are also specialized in blood-borne particle uptake and express surface markers such as SIGLEC-1 and MOMA-1.

Recent studies led to a growing understanding of the precise roles different splenic MФs play to maintain blood homeostasis, particularly in infectious diseases, in which pathogen elimination depends on the development of appropriate adaptive immune response. In this review, we addressed the roles of each one of

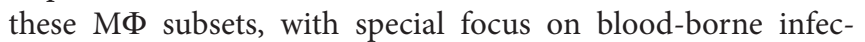
tions. We described the current knowledge on the effects of splenic microarchitecture and microenvironment on these MФs and reciprocal influence of these cells on spleen structure and functionality.

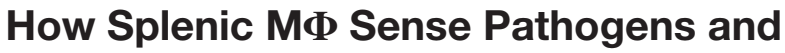 Damage-Associated Self-Molecules?}

Splenic MФs have two main protective activities during bloodborne infections. The first and most well characterized is phagocytosis and elimination of pathogens from circulation. However, beyond the task of eliminating blood-borne pathogens, splenic MФs can play a prominent role in immune system activation. To properly execute these functions, they are provided with a large variety of pattern-recognition receptors (PRRs) that recognize pathogen-associated molecular patterns (PAMPs) and damage-associated molecular patterns (DAMPs). Engagement of Toll-like receptor (TLR) 4 by pathogen molecules, such as lipopolysaccharides (LPS) from Gram-negative bacteria is fundamental for the induction of a proinflammatory gene and protein expression signature in $\mathrm{M} \Phi$ s, which ultimately leads to innate immune activation (6). This also holds true for several other interactions such as TLR2 and/or TLR4 with glycosylphosphatidylinositol (GPI) anchors from Trypanosoma and Plasmodium parasites $(7,8)$ and TLR9 engagement by CpG motifs found in bacterial (9) and plasmodial DNA (10).

On the other hand, TLRs recognize DAMPs in situations of tissue injury. For example, heat shock proteins (HSPs) are endogenous damage signals (molecules released by cells under stress or necrotic cell death) and bind to TLR2 and TLR4 in MФs, inducing these cells to produce proinflammatory cytokines and to express costimulatory molecules (11). Release of HSPs to circulation has been reported during sepsis (12) as well as production of HSP homologues by pathogens such as Plasmodium parasites (13). Also, TLRs - especially TLR2 and TLR4 - can recognize extracellular matrix components such as fibronectin (14). TLR4 engagement by fibronectin leads to $M \Phi$ activation in a similar fashion to what happens after LPS stimulation. Fibronectin is 
presumably secreted by fibroblasts inside the spleen. Thus, this molecule may be produced during blood-borne infections such as malaria, where profound changes in splenic microarchitecture following acute infection occur, leading to the accumulation of fibroblasts inside the Rp (15). Expression of fibronectin-binding proteins (FnBPs) by Staphylococcus aureus is important to bacterial uptake by $\mathrm{M} \Phi$ s in inflammatory situations through binding of very late antigen 5 (VLA-5) (16). Therefore, it is reasonable to question whether TLR2 and/or TLR4 expressed in MФs are engaged by fibronectin in those situations. Importantly, S. aureus FnBPs are crucial for the development of sepsis (16).

Another DAMP that can induce M $\Phi$ activation is the high mobility group box protein 1 (HMGB1), an intracellular DNAbinding protein involved in chromatin remodeling and transcription regulation (17). Extracellular HMGB1 binds to different endogenous ligands that are recognized by receptors such as TLR4, as well as the receptor for advanced glycation end products (RAGE) (18), and triggers inflammatory responses by the innate immune system. Release of HMGB1 by splenic MФs occurs upon extensive splenic cell apoptosis, a feature commonly observed during sepsis. Indeed, HMGB1 is released into the extracellular milieu during sepsis and neutralization of this protein by monoclonal antibody treatment blocks sepsis development (19). Abundant splenic cell apoptosis is also typical in rodent malaria, at the peak of acute infection (20). In human malaria, endogenous HMGB1 serum levels are significantly higher in patients with severe disease compared to uncomplicated cases (21), suggesting that HMGB1 might also be involved in the development of immunopathology. Thus, it would not be surprising if acute immune response to Plasmodium and consequent immunopathology could be suppressed in great extent with neutralization of HMGB1.

Splenic MФ receptors also include C-type lectin receptors (CLRs), such as dectin-1, mannose receptor, and dendritic cellspecific intercellular adhesion molecule-3-grabbing non-integrin (DC-SIGN). CLRs have multiple functions in the immune system, including pathogen recognition and neutralization (22). Additionally, the liver synthesizes mannose-binding protein (MBP) during infectious diseases. This protein activates the complement system in order to form the membrane attack complex (MAC), and, more importantly in the spleen, to opsonize microorganisms such as virus (23) or protozoan parasites such as Trypanosoma cruzi (24). Scavenger receptors (SRs), such as SR-A1 and MARCO, are also expressed in splenic MФs and likewise bind both self and pathogen molecules - more specificities of these receptors will be discussed later in this review. Among class B SRs, CD36 is known to mediate the uptake of oxidized low-density lipoprotein (oxLDL) and apoptotic cells, but also promotes phagocytosis of $S$. aureus bacteria by peritoneal MФs (25). However, CD36 mediates cytoadherence of Plasmodiuminfected red blood cells (iRBCs) to microvascular endothelium (26), a process supposed to avoid parasite clearance inside the spleen. The role of CD36 in recognizing this parasite by splenic

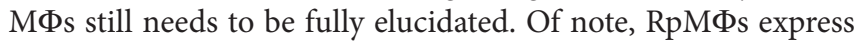
constitutively this molecule, which implies a possible role for this receptor in antiplasmodial immunity. This is a clear example of a receptor capable of mediating the recognition of both self and non-self molecules, implicating RpM $\Phi$ s with both blood homeostasis and control of blood-borne infections.

Among cytoplasmic PRRs, splenic MФs express molecules from the NOD-like receptor (NLR) family (27). For example, disturbance of cellular ionic gradient activates the pyrin subfamily member NLRP3, leading to inflammasome complex formation and in consequence to the release of inflammatory cytokines IL-1 $\beta$ and IL-18. Hemozoin, a disposal product formed from hemoglobin digestion by Plasmodium parasites, triggers the NLRP3 inflammasome in bone marrow-derived macrophages (BMDMs) (28), mediating the production of proinflammatory cytokines by these cells. Furthermore, the NLRP3 inflammasome is activated in mouse RpM $\Phi$ s and human peripheral monocytes during acute malaria - although large amounts of IL- $1 \beta$ are only produced after stimulation with LPS (29). Interestingly, in mice, this process is mediated by the purinergic $\mathrm{P} 2 \times 7$ receptor which recognizes extracellular ATP. ATP accumulates in Plasmodium-iRBCs and is released into the extracellular milieu through ion channels in the erythrocyte membrane or upon iRBC rupture (30).

\section{Role of RpMФs in Blood-Borne Infections}

As stated previously, RpMФs form a vast network inside the Rp, and although there is no consensus about the origin of RpMФs, recent data indicate that these $\mathrm{M} \Phi$ s are maintained by local proliferation during physiological conditions (31). Conversely, in some pathological conditions, circulating monocytes are able to differentiate into RpMФs (32). RpM $\Phi$ population comprises macrophage colony-stimulating factor (M-CSF)-dependent and M-CSF-independent cells (33). M-CSF-dependent RpM $\Phi$ s are efficient phagocytes and produce proinflammatory cytokines such as TNF- $\alpha$ and type I IFNs and are highly responsive to prostaglandin E2 (PGE2). In contrast, M-CSF-independent BMDMs are less efficient phagocytes that produce high amounts of PGE2 (34). If this is a general feature of M-CSF-independent $M \Phi$ populations, M-CSF-independent RpM $\Phi$ s might influence the activity of M-CSF-dependent RpM $\Phi$ s.

Venous cords and sinuses render the splenic Rp bloodstream in a slow pace. This characteristic allows for the filtering function of the spleen and favors elimination of aberrant red blood cells (RBCs) or Plasmodium-iRBCs (35). Of note, development of RpMФs relies on the expression of the transcription factor Spi-C, which is induced by free heme from RBC degradation (32). Thus, iron homeostasis - which conversely is controlled by RpM $\Phi$ s - might play a role in RpM $\Phi$ development. Splenic structure also facilitates the control of numerous blood-borne

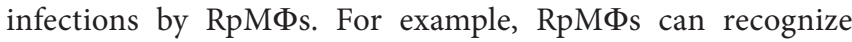
the capsular polysaccharide glucuronoxylomannan (GXM) from Cryptococcus neoformans and subsequently phagocytize the bacteria (36). RpMФs can also eliminate Streptococcus pneumoniae under conditions of splenomegaly (37). However, these $M \Phi$ s are permissive to intracellular growth of Salmonella typhimurium (38).

Red pulp macrophages have also been implicated in the control of blood-stage malaria (35). Nevertheless, in experimental Plasmodium yoelii infection, spleen remodeling facilitates iRBC 
adherence to the vascular endothelium and, in consequence, allows parasites to escape from phagocytes (15). Interestingly, a proportion of Rp phagocytes exhibit strong labeling for F4/80 and CD11c, a phenotype shared by RpMФs and DCs (39). This population participates in the early clearance of Plasmodium chabaudi parasites, but it sharply declines at the parasitemia peak. RpMФs have a slow turnover rate and possibly undergo cell death after ingesting Plasmodium-iRBCs due to the toxic effects of hemozoin. RpMФs, which are primarily required to maintain tissue homeostasis, might be substituted by inflammatory phagocytes as well as by $\mathrm{M} \Phi$ s derived from inflammatory monocytes. An alternative explanation is downregulation of the F4/80 molecule upon M $\Phi$ activation, as reported during mycobacterial infection (40).

Several mechanisms mediate $\mathrm{RBC}$ recognition and clearance by RpMФs. One of the most studied mechanisms is the antibody binding to altered self components such as Band 3 clusters (41) or phosphatidylserine residues exposed in the outer leaflet of RBC membrane (42). In these cases, natural antibodies and complement system proteins opsonize RBCs though recognition of Band 3 clusters or phosphatidylserine residues. Another important interaction involved in RBC phagocytosis by RpM $\Phi$ s is the ligation of CD47 to Signal Regulatory Protein alpha (SIRP $\alpha$ ) (43). CD47 is a self-molecule important to avoid clearance by phagocytes, which is ubiquitously expressed on many cell types, including RBCs. CD47 expression on RBCs is an inhibitory signal for phagocytosis (44), but RBCs expressing a modified isoform of this molecule are phagocytized by RpM $\Phi$ s through SIRP $\alpha$ binding (43). Interestingly, the conformation-dependent anti-CD47 antibody 2D3 binds sickle RBCs preferentially (45), which might explain the enhanced phagocytosis of sickle RBCs inside spleen. A recent study showed that $P$. yoelii parasites preferentially infect young RBCs expressing high levels of CD47 and, in consequence, escape from splenic clearance (46). Furthermore, enhanced resistance to $P$. yoelii observed in CD47-deficient mice is associated with a larger population of RpM $\Phi$ s that ingest more iRBCs than wild-type counterparts. These findings explain why individuals with mild genetic RBC disorders (e.g., sickle cell trait and glucose-6-phosphate dehydrogenase deficiency) are protected from lethal malaria due to enhanced RBC phagocytosis.

Apart from being phagocytized by splenic MФs, PlasmodiumiRBCsarealso destroyed intravascularly as a consequence of plasma membrane damage upon release of free merozoites. Hemozoin, a disposal product formed from hemoglobin digestion by parasites, is released from lysed iRBCs. Furthermore, a massive destruction of non-infected RBCs occurs during blood-stage malaria, leading to increased hemoglobin levels in circulation [reviewed in Ref. (47)]. Another example of hemolysis induced by infections is observed in septicemia caused by Escherichia coli, which produces exotoxin $\alpha$-hemolysin (Hly $\alpha$ ) (48). Evidencing RpMФs crucial role in neutralizing toxic effects of hemoglobin, these $M \Phi$ s have high levels of intracellular heme due to RBC phagocytosis (2) and of free hemoglobin through the scavenger receptor CD163 (49). The enzyme heme-oxygenase $1(\mathrm{HO}-1)$ plays an important role in degrading free heme, which in excess causes toxicity to MФs (50). Importantly, RpM $\Phi$ s are able to control pathogen burden through control of iron availability. For example, RpMФs express the natural resistance associated macrophage protein-1 (NRAMP1) that is associated with protection against intraphagosomal pathogens, such as Mycobacterium bovis BCG, Leishmania donovani, or S. typhimurium. This molecule is a $\mathrm{pH}$-dependent metal transporter localized in phagosomal compartments, which reduces intraphagosomal iron levels derived from RBC phagocytosis (51). NRAMP1 synthesis is upregulated in IFN- $\gamma$-activated MФs (52), a condition likely to occur during acute blood-borne infections. RpMФs also limit pathogen iron uptake through TLR-mediated release of lipocalin-2, which can form complexes with pathogensecreted siderophores - molecules that help the collection of iron available for pathogens (53). RpMФs involvement in controlling excessive immune responses is suggested by studies on autoimmune syndromes, while a similar participation in infectious diseases remains to be established. For instance, RpMФs constitutively express peroxisome proliferator-activated receptor- $\gamma$ (PPAR- $\gamma$ ), which might be important to curb excessive immune responses to pathogens, in a similar manner to PPAR- $\gamma$ expressed on lung MФs upon S. pneumoniae infection (54). RPMФs can also prevent autoimmunity by producing anti-inflammatory cytokines such as TGF- $\beta$ and IL- 10 and by inducing generation of regulatory $\mathrm{T}$ (Treg) cells (55). Of note, there are many T cells scattered in Rp (55), and this population participates in acute immune responses to infections, such as blood-stage malaria (39). We present an illustrated scheme of the different roles of RpMФs in homeostasis and disease in Figure 2.

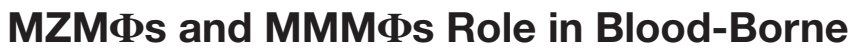 Infections}

Marginal zone macrophages and MMMФs have unique characteristics that contribute to rapid phagocytosis of pathogens and other particles. Thus, these MФs act like scavenger cells, developing pro- or anti-inflammatory responses depending on the nature of the interaction. MZMФs express SIGNR1 that binds to yeasts and the yeast-derived particle zymosan (4), to bacteria such as Mycobacterium tuberculosis (56), S. pneumoniae (57), E. coli, and S. typhimurium (58), and to virus such as human immunodeficiency virus (HIV) (4). This receptor recognizes carbohydrate antigens from blood-borne pathogens and mediates their subsequent internalization into phagosomes (4). Although SIGNR1 in peritoneal MФs cooperate with dectin-1 in zymosan uptake (59), these innate receptors colocalize poorly in MZMФs (60). Similar to classical complement pathway activation, but independently of antibodies, SIGNR1 also binds C1q and assembles the complex $\mathrm{C} 4 \mathrm{bC} 2 \mathrm{a}$ or $\mathrm{C} 3$ convertase that catalyzes C3b opsonin formation (61). This mechanism was shown to provide resistance to intravenous $S$. pneumoniae infection.

Expression of the scavenger receptor MARCO is upregulated

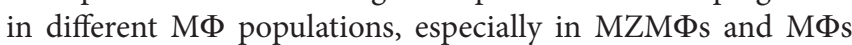
in the medullary cord of lymph nodes (3). MARCO was firstly reported to bind and mediate uptake of Gram-negative bacteria and also to recognize oxLDL [reviewed in Ref. (62)]. The structure of MARCO is similar to that of the Scavenger Receptor A1 (SR-A1, CD204), which plays a role in bacteria and virus recognition (3). TLR-mediated activation of BMDMs stimulates 


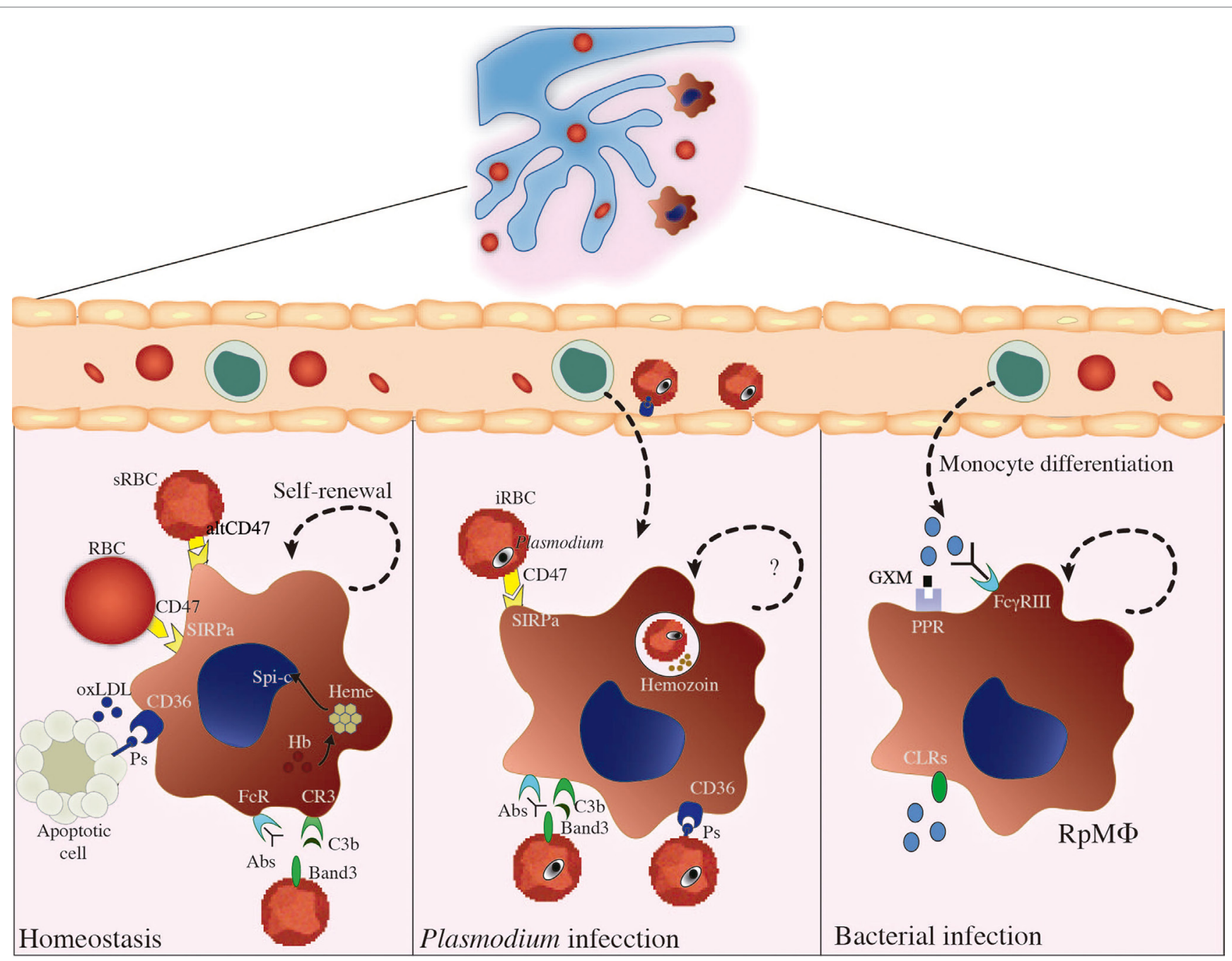

FIGURE 2 | RpMФ biology during homeostasis and infection. This figure summarizes the different roles of RpMФs in maintenance of host homeostasis and in the control of different infections. In the absence of infection (left), RpMФs play important roles in the uptake of apoptotic cells, oxidized LDL (oxLDL), or senescent RBCs (sRBCs) from the circulations, through interaction with receptors such as SIRP $\alpha, C D 36, C R 3$, or FcRs. CD47 expression on RBCs is an inhibitory signal for phagocytosis mediated by SIRP $\alpha$, but sRBCs expressing a modified isoform of this molecule (altCD47) are phagocytized by RpMФs. CD36 binds to phosphatidylserine (PS) and, alternatively, to oxLDL. RpMФs are also important for iron homeostasis, and conversely, iron homeostasis seems to control RpM $\Phi$ development, through the action of free heme on Spi-C transcriptional factor. In these situations, RpMФs have the ability of self-renewal by proliferation. Beyond the task of maintaining blood homeostasis, RpMФs contribute to control blood-borne infections such as malaria (center) or bacterial infections (right) lead to changes in RpM $\Phi$ function. Plasmodium-infected RBCs (iRBCs) are recognized through the same receptors that recognize sRBCs, such as SIRP $\alpha$, CR3, FcRs, or CD36, inferring a role for RpM $\Phi$ s in parasite clearance. However, the adherence of iRBCs to microvascular endothelium through CD36 prevents iRBC clearance inside the spleen. Interestingly, P. yoelii parasites preferentially infect young RBCs expressing high levels of CD47 and, in consequence, escape from splenic clearance. RpM $\Phi s$ also present with other receptors such as CLRs and PPRs, which in conjunct with FcyRlll contribute to recognition and elimination of bacteria from circulation. RpMФs can recognize the capsular polysaccharide glucuronoxylomannan (GXM) from Cryptococcus neoformans and subsequently phagocytize the bacteria. The

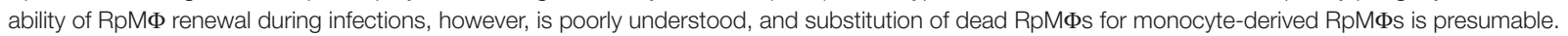

MARCO-mediated phagocytic activity (63). Furthermore, MARCO in MZMФs directly binds and mediates phagocytosis of E. coli and S. aureus bacteria (3). TLR engagement leads to activation of transcriptional mechanisms that increase phagocytosis and cell activation, and MARCO seems to work in conjunct with TLRs in order to mediate pathogen control (64).

Marginal zone macrophages and $M M M \Phi s$ are fundamental in the early control of Listeria monocytogenes bacteremia, as evaluated by depletion of these $\mathrm{M} \Phi$ s using a low dose of clodronate liposomes (65). T-cell responses are not affected in this experimental model, ruling out the participation of MZMФs and $M M M \Phi s$ as antigen-presenting cells. Similar findings were reported during infection with Neisseria meningitidis (64), thus it is likely that these $M \Phi$ s have a direct role in the elimination of bacteria from circulation. Conversely, adenoviruses colocalize with MZMФs as soon as a few minutes after intravenous injection in mice (66). MZMФs and MMMФs play a similar role in lymphocytic choriomeningitis virus (LCMV) infection, corroborating 
the importance of these MФs in first-line antiviral defense (67). On the other hand, localization of MZMФs and MMMФs in the interface between the bloodstream and lymphocyte-rich zones makes them suitable to bridge innate and adaptive immunity in several situations. For instance, mice lacking SRs MARCO and SR-A1 show a defective microarchitecture of the splenic MZ and an impaired T-independent type 2 response when challenged with pneumococcal polysaccharide (68). MMMФs also collaborate in cytotoxic T-cell activation by transferring antigen directly to $\mathrm{CD} 8 \alpha^{+} \mathrm{DCs}$, which are specialized in cross-presentation to CD8 ${ }^{+}$ T cells (69). This observation supports the use of the MMMФs antigen-concentrating capacity in therapeutic strategies for the development of antitumor immunity. The different roles of MZMФs and MMMФs in blood-borne infections are shown in Figure 3.

\section{Reciprocal Influence of Splenic Microenvironment and MФs}

In several aspects, splenic MФs shape splenic structure and/or microenvironment. The development of splenomegaly is typical in blood-borne infections, and it is characterized by profound changes in splenic microarchitecture, including remodeling of Rp (1). Given this, splenic MФs are expected to play a prominent role in the recruitment of different cell types during acute immune responses. For example, RpM $\Phi$ s recruit neutrophils into the spleen during early Candida infection by releasing CXCL1 and CXCL2, through autophagy-mediated depletion of the NF- $\mathrm{BB}$ inhibitor molecule A20 (70). Another example is the arresting of T cells inside the Rp during acute Plasmodium infection (39). RpMФs may produce CXCR3- and/or CCR5-binding chemokines by a mechanism similar to that observed during early Candida infection - CXCR3 and CCR5 are the main upregulated chemokine receptors in splenic $\mathrm{CD}^{+} \mathrm{T}$ cells during acute blood-stage malaria (71). However, splenic MФs might also act on splenic microenvironment after an acute infection. For example, apoptotic cell uptake induces CCL22 production by MMMФs, which in turn induces Foxp $3^{+}$Tregs and DCs recruitment and accumulation, leading to a state of tolerance (72). Since the accumulation of apoptotic cells is a normal feature after acute blood-borne infections (20), a similar mechanism possibly takes place. RPMФs can also prevent autoimmunity by producing anti-inflammatory cytokines such as TGF- $\beta$ and IL-10 and by inducing the generation of Treg cells (55). These cytokines may be important - besides limiting autoimmunity - to curb an excessive immune response that could be dangerous to the host after pathogen clearance.

Conversely, the splenic structure and its microenvironment seem to play pivotal roles in $\mathrm{M} \Phi$ homing and function. For instance, arrangement of sinusoidal endothelial cells inside Rp hampers the circulation of aging and/or iRBCs (1), facilitating their trapping inside Rp and posterior phagocytosis by RpMФs. Importantly, the cytokine milieu in the microenvironment - which varies throughout an acute infection - may also dictate RpM $\Phi$ function. Classic M1 MФs have an enhanced capacity to accumulate iron, which positively influences the maintenance of these cells in a proinflammatory state. On the other hand, alternative M2 MФs have an increased ability to release iron, and increased iron availability in the microenvironment seemingly favors tissue remodeling [reviewed in Ref. (73)]. These effects can easily be associated with RpMФs especially considering their role in iron uptake (1), thus it

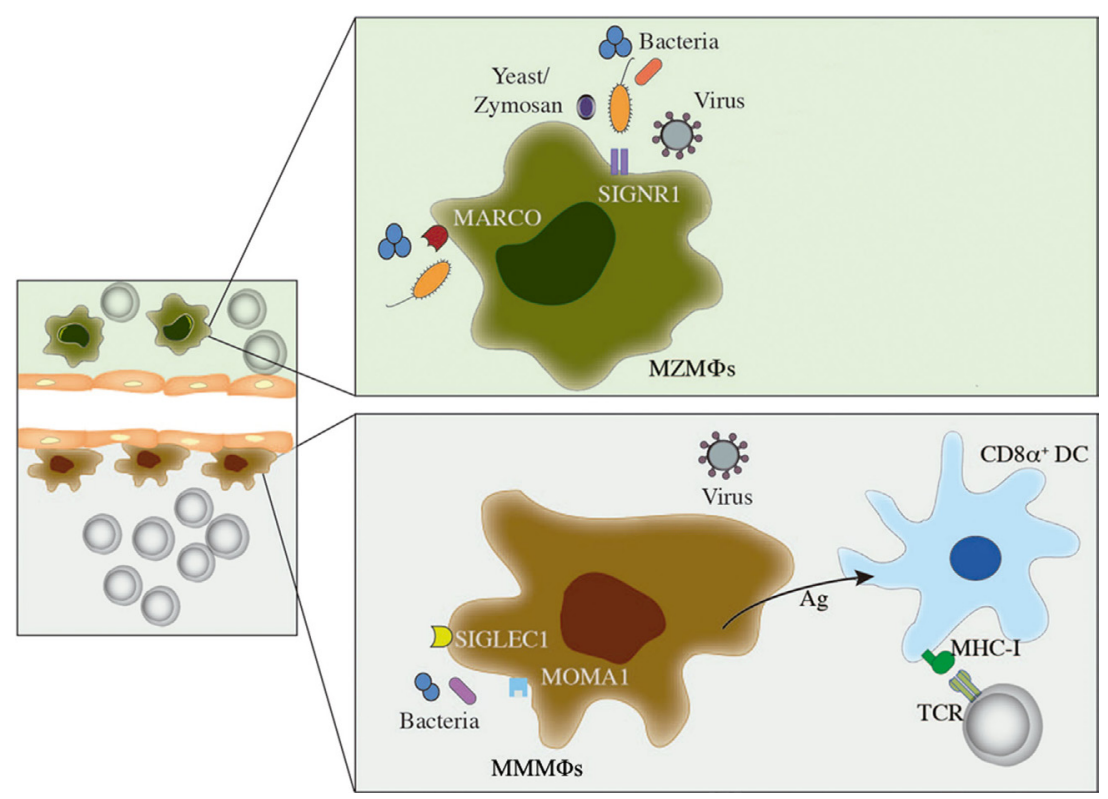

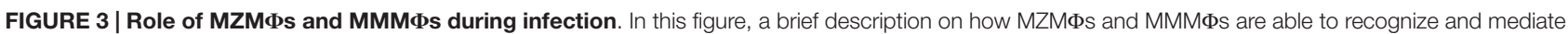
protection against blood-borne pathogens is shown. MZMФs (above) can recognize bacterial and viral infections by receptors such as MARCO or SIGNR1, which usually induce internalization and further pathogen degradation. A similar feature can be depicted for MMMФS, where MOMA-1 or SIGLEC can mediate pathogen recognition and elimination from circulation. MMMФs can also interact with CD8 $\alpha^{+}$dendritic cells (DCs), which ultimately lead to CD8 ${ }^{+}$T-cell activation. 
TABLE 1 | Overview of splenic MФ subsets.

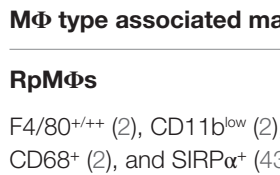

$\mathrm{CD}^{+} 8^{+}(2)$, and $\operatorname{SIRP} \alpha^{+}(43)$
Connection to immune response

- Uptake of aging or apoptotic RBCs (2)

- Limitation of autoimmunity (IL-10 and TGF $\beta$ in resolution of inflammation) (55)

- Induction of Tregs by IL-10 production (55)

- Phagocytosis of blood-borne pathogens (35-38)

- Iron homeostasis (1, 50-53)

- Clearance of modified LDL (1)

- Tl-2 B cell responses (68)

- Phagocytosis of blood-borne pathogens $(3,4,65,67)$
Associated pathogens

Plasmodium (35), Cryptococcus neoformans (36), Streptococcus pneumoniae (37), Salmonella typhimurium (38)

\section{MZMФs}

SIGNR1+ $(3,4), \mathrm{F}^{4} / 80^{+/-}(3,4)$, $\mathrm{MARCO}^{+}(3,4)$, lymphotoxin, and TNF receptors $(75,76)$
Staphylococcus aureus (3), Listeria monocytogenes (65), Escherichia coli (3), HIV (4), LCMV (67)

\section{МММФs}

SigLec- $1^{+}\left(\mathrm{CD} 169^{+}\right)$(5), MOMA-1+ (5) $\mathrm{F} 4 / 80^{+/-}(5)$, lymphotoxin, and TNF receptors $(75,76)$

- Indirect activation of CD8+ T cells (69)

- Phagocytosis of blood-borne pathogens (67)
Listeria monocytogenes (65) LCMV (67)

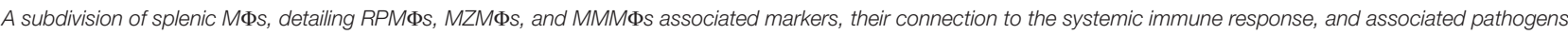

The respective references from each feature are detailed inside the table.

is possible that RpMФs play distinct roles as M1- or M2-skewing microenvironments may occur during the beginning of an acute blood-borne infection or after pathogen clearance, respectively. Furthermore, the MZ contains a large number of resident cells that apparently depend on each other for their localization, thereby establishing and maintaining MZintegrity (1). For example, studies in which B cells were absent from the time of birth or in which they are depleted led to disappearance of MZMФs and MMMФs (74). Thus, the continuous interaction between resident and transmigrating cells inside the spleen MZ is crucial for efficient homing of MZMФs and MMMФs as well as for efficient removal and destruction of blood-borne pathogens by these cells. Lymphotoxin (LT) and TNF also influence the dynamics of MZMФs and MMMФs. $L$. donovani-infected mice have profound changes in the splenic $\mathrm{MZ}$ including loss of MZMФs, which depend on TNF signaling that may increase MZMФs susceptibility to parasite-induced cell death (75). These changes block lymphocyte traffic in the white pulp, impairing the development of an appropriate adaptive immune response. In another case, MZ B cells secrete LT- $\alpha 1 \beta 2$, and this leads to induction of a range of chemokines that could, in turn, influence lodging and retention of MZMФs (76).

\section{Concluding Remarks}

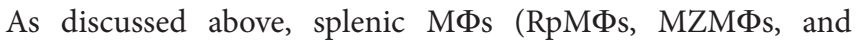
MMMФs) play important roles in the control of blood-borne

\section{References}

1. Mebius RE, Kraal G. Structure and function of the spleen. Nat Rev Immunol (2005) 5:606-16. doi:10.1038/nri1669

2. Kohyama M, Ise W, Edelson BT, Wilker PR, Hildner K, Mejia C, et al. Role for Spi-C in the development of red pulp macrophages and splenic iron homeostasis. Nature (2009) 457:318-21. doi:10.1038/nature07472

3. Elomaa O, Kangas M, Sahlberg C, Tuukkanen J, Sormunen R, Liakka I, et al. Cloning of a novel bacteria-binding receptor structurally related to scavenger receptors and expressed in a subset of macrophages. Cell (1995) 80:603-9. doi:10.1016/0092-8674(95)90514-6 infections and shape several aspects of innate and adaptive immune responses (Table 1). Thus, a clear concept on the nature of splenic $M \Phi$ populations can be drawn, in which their interplay with the splenic microenvironment guarantees efficient control of blood-borne pathogens and maintenance of homeostasis following these infections. At the same time, the splenic structure is likely fundamental for proper localization and function of these MФs. However, several questions on the nature and function of these cells are still unanswered, especially on (a) the development of splenic $M \Phi$ s during embryogenesis, (b) the exact signals required for the homeostatic maintenance of these cells, and (c) the extent of how important each of these subsets are for the development of immunity against blood-borne infections. The development of mouse models to accurately study the distinct roles of RpMФs,

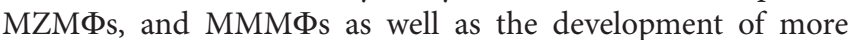
detailed studies on signaling pathways and epigenetic modifications on genes involved in the function of these cells will be of great utility to solve these questions.

\section{Acknowledgments}

This study was supported by grants from the São Paulo Research Foundation (FAPESP) 2013/07140-2 (ML) and 2014/00810-5 (HS) and from National Council for Scientific and Technological Development (CNPq) 303676/2014-0 (ML) and 448765/2014-4 (ML). The funders had no role in the preparation of the manuscript.

4. Geijtenbeek TB, Groot PC, Nolte MA, van Vliet SJ, Gangaram-Panday ST, van Duijnhoven GC, et al. Marginal zone macrophages express a murine homologue of DC-SIGN that captures blood-borne antigens in vivo. Blood (2002) 100:2908-16. doi:10.1182/blood-2002-04-1044

5. Kraal G, Janse M. Marginal metallophilic cells of the mouse spleen identified by a monoclonal antibody. Immunology (1986) 58:665-9.

6. Liu G, Xia XP, Gong SL, Zhao Y. The macrophage heterogeneity: difference between mouse peritoneal exudate and splenic F4/80+ macrophages. J Cell Physiol (2006) 209:341-52. doi:10.1002/jcp.20732

7. Campos MA, Almeida IC, Takeuchi O, Akira S, Valente EP, Procópio DO, et al. Activation of toll-like receptor-2 by glycosylphosphatidylinositol anchors 
from a protozoan parasite. J Immunol (2001) 167:416-23. doi:10.4049/ jimmunol.167.1.416

8. Krishnegowda G, Hajjar AM, Zhu J, Douglass EJ, Uematsu S, Akira S, et al. Induction of proinflammatory responses in macrophages by the glycosylphosphatidylinositols of Plasmodium falciparum: cell signaling receptors, glycosylphosphatidylinositol (GPI) structural requirement, and regulation of GPI activity. J Biol Chem (2005) 280:8606-16. doi:10.1074/jbc.M413541200

9. Hemmi H, Takeuchi O, Kawai T, Kaisho T, Sato S, Sanjo H, et al. A toll-like receptor recognizes bacterial DNA. Nature (2000) 408:740-5. doi: $10.1038 / 35047123$

10. Parroche P, Lauw FN, Goutagny N, Latz E, Monks BG, Visintin A, et al. Malaria hemozoin is immunologically inert but radically enhances innate responses by presenting malaria DNA to toll-like receptor 9. Proc Natl Acad Sci U S A (2007) 104:1919-24. doi:10.1073/pnas.0608745104

11. Ohashi K, Burkart V, Flohe S, Kolb H. Cutting edge: heat shock protein 60 is a putative endogenous ligand of the toll-like receptor-4 complex. J Immunol (2000) 164:558-61. doi:10.4049/jimmunol.164.2.558

12. Zhang R, Wan XJ, Zhang X, Kang QX, Bian JJ, Yu GF, et al. Plasma HSPA12B is a potential predictor for poor outcome in severe sepsis. PLoS One (2014) 9:e101215. doi:10.1371/journal.pone.0101215

13. Bianco AE, Favaloro JM, Burkot TR, Culvenor JG, Crewther PE, Brown GV, et al. A repetitive antigen of Plasmodium falciparum that is homologous to heat shock protein 70 of Drosophila melanogaster. Proc Natl Acad Sci U S A (1986) 83:8713-7. doi:10.1073/pnas.83.22.8713

14. Okamura Y, Watari M, Jerud ES, Young DW, Ishizaka ST, Rose J, et al. The extra domain A of fibronectin activates toll-like receptor 4. J Biol Chem (2001) 276:10229-33. doi:10.1074/jbc.M100099200

15. Martin-Jaular L, Ferrer M, Calvo M, Rosanas-Urgell A, Kalko S, Graewe S, et al. Strain-specific spleen remodelling in Plasmodium yoelii infections in $\mathrm{Balb} / \mathrm{c}$ mice facilitates adherence and spleen macrophage-clearance escape. Cell Microbiol (2011) 13:109-22. doi:10.1111/j.1462-5822.2010.01523.x

16. Shinji H, Seki K, Tajima A, Uchida A, Masuda S. Fibronectin bound to the surface of Staphylococcus aureus induces association of very late antigen 5 and intracellular signaling factors with macrophages. Infect Immun (2003) 71:140-6. doi:10.1128/IAI.71.1.140-146.2003

17. Stros M. HMGB proteins: interactions with DNA and chromatin. Biochim Biophys Acta (2010) 1799:101-13. doi:10.1016/j.bbagrm.2009.09.008

18. Hori O, Brett J, Slattery T, Cao R, Zhang J, Chen JX, et al. The receptor for advanced glycation end products (RAGE) is a cellular binding site for amphoterin. Mediation of neurite outgrowth and coexpression of RAGE and amphoterin in the developing nervous system. J Biol Chem (1995) 270:25752-61. doi:10.1074/jbc.270.43.25752

19. Qin S, Wang H, Yuan R, Li H, Ochani M, Ochani K, et al. Role of HMGB1 in apoptosis-mediated sepsis lethality. J Exp Med (2006) 203:1637-42. doi:10.1084/jem.20052203

20. Elias RM, Sardinha LR, Bastos KR, Zago CA, da Silva AP, Alvarez JM, et al. Role of CD28 in polyclonal and specific $\mathrm{T}$ and $\mathrm{B}$ cell responses required for protection against blood stage malaria. J Immunol (2005) 174:790-9. doi:10.4049/jimmunol.174.2.790

21. Higgins SJ, Xing K, Kim H, Kain DC, Wang F, Dhabangi A, et al. Systemic release of high mobility group box 1 (HMGB1) protein is associated with severe and fatal Plasmodium falciparum malaria. Malar J (2013) 12:105. doi:10.1186/1475-2875-12-105

22. Marodi L, Korchak HM, Johnston RB Jr. Mechanisms of host defence against Candida species I. Phagocytosis by monocytes and monocyte-derived macrophages. J Immunol (1991) 146:2783-9.

23. Nguyen DG, Hildreth JE. Involvement of macrophage mannose receptor in the binding and transmission of HIV by macrophages. Eur J Immunol (2003) 33:483-93. doi:10.1002/immu.200310024

24. Kahn SJ, Wleklinski M, Ezekowitz RA, Coder D, Aruffo A, Farr A. The major surface glycoprotein of Trypanosoma cruzi amastigotes are ligands of the human serum mannose-binding protein. Infect Immun (1996) 64:2649-56.

25. Stuart LM, Deng J, Silver JM, Takahashi K, Tseng AA, Hennessy EJ, et al. Response to Staphylococcus aureus requires CD36-mediated phagocytosis triggered by the COOH-terminal cytoplasmic domain. J Cell Biol (2005) 170:477-85. doi:10.1083/jcb.200501113

26. Mota MM, Jarra W, Hirst E, Patnaik PK, Holder AA. Plasmodium chabaudiinfected erythrocytes adhere to CD36 and bind to microvascular endothelial cells in an organ-specific way. Infect Immun (2000) 68:4135-44. doi:10.1128/ IAI.68.7.4135-4144.2000

27. Guarda G, Zenger M, Yazdi AS, Schroder K, Ferrero I, Menu P, et al. Differential expression of NLRP3 among hematopoietic cells. JImmunol (2011) 186:2529-34. doi:10.4049/jimmunol.1002720

28. Kalantari P, DeOliveira RB, Chan J, Corbett Y, Rathinam V, Stutz A, et al. Dual engagement of the NLRP3 and AIM2 inflammasomes by Plasmodium-derived hemozoin and DNA during malaria. Cell Rep (2014) 6:196-210. doi:10.1016/j. celrep.2013.12.014

29. Ataide MA, Andrade WA, Zamboni DS, Wang D, Souza Mdo C, Franklin BS, et al. Malaria-induced NLRP12/NLRP3-dependent caspase-1 activation mediates inflammation and hypersensitivity to bacterial superinfection. PLoS Pathog (2014) 10:e1003885. doi:10.1371/journal.ppat.1003885

30. Levano-Garcia J, Dluzewski AR, Markus RP, Garcia CR. Purinergic signalling is involved in the malaria parasite Plasmodium falciparum invasion to red blood cells. Purinergic Signal (2010) 6:365-72. doi:10.1007/ s11302-010-9202-y

31. Hashimoto D, Chow A, Noizat C, Teo P, Beasley MB, Leboeuf M, et al. Tissueresident macrophages self-maintain locally throughout adult life with minimal contribution from circulating monocytes. Immunity (2013) 38:792-804. doi:10.1016/j.immuni.2013.04.004

32. Haldar M, Kohyama M, So AY, Kc W, Wu X, Briseño CG, et al. Heme-mediated SPI-C induction promotes monocyte differentiation into iron-recycling macrophages. Cell (2014) 156:1223-34. doi:10.1016/j.cell.2014.01.069

33. Naito M, Hayashi SI, Yoshida H, Takahashi K. Abnormal differentiation of tissue macrophage populations in "osteopetrosis" (op) mice defective in the production of macrophage colony-stimulating factor (M-CSF) or CSF-1. Am J Pathol (1991) 139:657-67.

34. Rutherford MS, Schook LB. Differential immunocompetence of macrophages derived using macrophage or granulocyte-macrophage colony-stimulating factor. J Leukoc Biol (1992) 51:69-76.

35. Schnitzer B, Sodeman T, Mead ML, Contacos PG. Pitting function of the spleen in malaria: ultrastructural observations. Science (1972) 177:175-7. doi:10.1126/science.177.4044.175

36. De Jesus M, Park CG, Su Y, Goldman DL, Steinman RM, Casadevall A. Spleen deposition of Cryptococcus neoformans capsular glucuronoxylomannan in rodents occurs in red pulp macrophages and not marginal zone macrophages expressing the C-type lectin SIGN-R1. Med Mycol (2008) 46:153-62. doi:10.1080/13693780701747182

37. Kirby AC, Beattie L, Maroof A, van Rooijen N, Kaye PM. SIGNR1-negative red pulp macrophages protect against acute streptococcal sepsis after Leishmania donovani-induced loss of marginal zone macrophages. Am J Pathol (2009) 175:1107-15. doi:10.2353/ajpath.2009.090258

38. Salcedo SP, Noursadeghi M, Cohen J, Holden DW. Intracellular replication of Salmonella typhimurium strains in specific subsets of splenic macrophages in vivo. Cell Microbiol (2001) 3:587-97. doi:10.1046/j.1462-5822.2001.00137.x

39. Borges da Silva H, Fonseca R, Cassado Ados A, Machado de Salles É, de Menezes MN, Langhorne J, et al. In vivo approaches reveal a key role for DCs in $\mathrm{CD}^{+} \mathrm{T}$ cell activation and parasite clearance during the acute phase of experimental blood-stage malaria. PLoS Pathog (2015) 11:e1004598. doi:10.1371/ journal.ppat.1004598

40. Ezekowitz RA, Gordon S. Down-regulation of mannosyl receptor-mediated endocytosis and antigen F4/80 in bacillus Calmette-Guérin-activated mouse macrophages. Role of T lymphocytes and lymphokines. J Exp Med (1982) 155:1623-37. doi:10.1084/jem.155.6.1623

41. Kay MM, Goodman SR, Sorensen K, Whitfield CF, Wong P, Zaki L, et al. Senescent cell antigen is immunologically related to band 3. Proc Natl Acad Sci U S A (1983) 80:1631-5. doi:10.1073/pnas.80.6.1631

42. Boas FE, Forman L, Beutler E. Phosphatidylserine exposure and red cell viability in red cell aging and in hemolytic anemia. Proc Natl Acad Sci U S A (1998) 95:3077-81. doi:10.1073/pnas.95.6.3077

43. Burger P, Hilarius-Stokman P, de Korte D, van den Berg TK, van Bruggen R. CD47 functions as a molecular switch for erythrocyte phagocytosis. Blood (2012) 119:5512-21. doi:10.1182/blood-2011-10-386805

44. Olsson M, Oldenborg PA. CD47 on experimentally senescent murine RBCs inhibits phagocytosis following Fc gamma receptor-mediated but not scavenger receptor-mediated recognition by macrophages. Blood (2008) 112:4259-67. doi:10.1182/blood-2008-03-143008 
45. Hillery CA, Scott JP, Du MC. The carboxy-terminal cell-binding domain of thrombospondin is essential for sickle red blood cell adhesion. Blood (1999) 94:302-9.

46. Banerjee R, Khandelwal S, Kozakai Y, Sahu B, Kumar S. CD47 regulates the phagocytic clearance and replication of the Plasmodium yoelii malaria parasite. Proc Natl Acad Sci U S A (2015) 112:3062-7. doi:10.1073/pnas.1418 144112

47. Haldar K, Mohandas N. Malaria, erythrocytic infection, and anemia. Hematology Am Soc Hematol Educ Program (2009) 2009:87-93. doi:10.1182/ asheducation-2009.1.87

48. Grimminger F, Rose F, Sibelius U, Meinhardt M, Pötzsch B, Spriestersbach R, et al. Human endothelial cell activation and mediator release in response to the bacterial exotoxins Escherichia coli hemolysin and staphylococcal alpha-toxin. J Immunol (1997) 159:1909-16.

49. Kristiansen M, Graversen JH, Jacobsen C, Sonne O, Hoffman HJ, Law SK, et al. Identification of the haemoglobin scavenger receptor. Nature (2001) 409:198-201. doi:10.1038/35051594

50. Kovtunovych G, Eckhaus MA, Ghosh MC, Ollivierre-Wilson H, Rouault TA. Dysfunction of the heme recycling system in heme oxygenase 1-deficient mice: effects on macrophage viability and tissue iron distribution. Blood (2010) 116:6054-62. doi:10.1182/blood-2010-03-272138

51. Vidal S, Tremblay ML, Govoni G, Gauthier S, Sebastiani G, Malo D, et al. The Ity/Lsh/Bcg locus: natural resistance to infection with intracellular parasites is abrogated by disruption of the Nramp1 gene. J Exp Med (1995) 182:655-66. doi:10.1084/jem.182.3.655

52. Fritsche G, Dlaska M, Barton H, Theurl I, Garimorth K, Weiss G. Nramp1 functionality increases inducible nitric oxide synthase transcription via stimulation of IFN regulatory factor 1 expression. J Immunol (2003) 171:1994-8. doi:10.4049/jimmunol.171.4.1994

53. Flo TH, Smith KD, Sato S, Rodriguez DJ, Holmes MA, Strong RK, et al. Lipocalin 2 mediates an innate immune response to bacterial infection by sequestrating iron. Nature (2004) 432:917-21. doi:10.1038/nature03104

54. Gautier EL, Chow A, Spanbroek R, Marcelin G, Greter M, Jakubzick C, et al. Systemic analysis of PPAR $\gamma$ in mouse macrophage populations reveals marked diversity in expression with critical roles in resolution of inflammation and airway immunity. J Immunol (2012) 189:2614-24. doi:10.4049/ jimmunol.1200495

55. Kurotaki D, Kon S, Bae K, Ito K, Matsui Y, Nakayama Y, et al. CSF-1-dependent red pulp macrophages regulate CD4 T cell responses. JImmunol (2011) 186:2229-37. doi:10.4049/jimmunol.1001345

56. Koppel EA, Ludwig IS, Hernandez MS, Lowary TL, Gadikota RR, Tuzikov $\mathrm{AB}$, et al. Identification of the mycobacterial carbohydrate structure that binds the C-type lectins DC-SIGN, L-SIGN and SIGNR1. Immunobiology (2004) 209:117-27. doi:10.1016/j.imbio.2004.03.003

57. Lanoue A, Clatworthy MR, Smith P, Green S, Townsend MJ, Jolin HE, et al. SIGN-R1 contributes to protection against lethal pneumococcal infection in mice. J Exp Med (2004) 200:1383-93. doi:10.1084/jem.20040795

58. Nagaoka K, Takahara K, Tanaka K, Yoshida H, Steinman RM, Saitoh S, et al. Association of SIGNR1 with TLR4-MD-2 enhances signal transduction by recognition of LPS in gram-negative bacteria. Int Immunol (2005) 17:827-36. doi:10.1093/intimm/dxh264

59. Taylor PR, Brown GD, Herre J, Williams DL, Willment JA, Gordon S. The role of SIGNR1 and the beta-glucan receptor (dectin-1) in the nonopsonic recognition of yeast by specific macrophages. J Immunol (2004) 172:157-62. doi:10.4049/jimmunol.172.2.1157

60. Reid DM, Montoya M, Taylor PR, Borrow P, Gordon S, Brown GD, et al. Expression of the beta-glucan receptor, Dectin-1, on murine leukocytes in situ correlates with its function in pathogen recognition and reveals potential roles in leukocyte interactions. J Leukoc Biol (2004) 76:86-94. doi:10.1189/ jlb.0104031

61. Kang YS, Do Y, Lee HK, Park SH, Cheong C, Lynch RM, et al. A dominant complement fixation pathway for pneumococcal polysaccharides initiated by SIGN-R1 interacting with C1q. Cell (2006) 125:47-58. doi:10.1016/j. cell.2006.01.046

62. Gough PJ, Gordon S. The role of scavenger receptors in the innate immune system. Microbes Infect (2000) 2:305-11. doi:10.1016/S1286-4579(00)00297-5
63. Doyle SE, O'Connell RM, Miranda GA, Vaidya SA, Chow EK, Liu PT, et al. Toll-like receptors induce a phagocytic gene program through p38. J Exp Med (2004) 199:81-90. doi:10.1084/jem.20031237

64. Chen Y, Wermeling F, Sundqvist J, Jonsson AB, Tryggvason K, Pikkarainen T, et al. A regulatory role for macrophage class A scavenger receptors in TLR4mediated LPS responses. Eur J Immunol (2010) 40:1451-60. doi:10.1002/ eji.200939891

65. Aichele P, Zinke J, Grode L, Schwendener RA, Kaufmann SH, Seiler P. Macrophages of the splenic marginal zone are essential for trapping of bloodborne particulate antigen but dispensable for induction of specific $\mathrm{T}$ cell responses. J Immunol (2003) 171:1148-55. doi:10.4049/jimmunol.171.3.1148

66. Di Paolo NC, Miao EA, Iwakura Y, Murali-Krishna K, Aderem A, Flavell RA, et al. Virus binding to a plasma membrane receptor triggers interleukin-1 alpha-mediated proinflammatory macrophage response in vivo. Immunity (2009) 31(1):110-21. doi:10.1016/j.immuni.2009.04.015

67. Seiler P, Aichele P, Odermatt B, Hengartner H, Zinkernagel RM, Schwendener RA. Crucial role of marginal zone macrophages and marginal zone metallophils in the clearance of lymphocytic choriomeningitis virus infection. Eur J Immunol (1997) 27:2626-33. doi:10.1002/eji.1830271023

68. Chen Y, Pikkarainen T, Elomaa O, Soininen R, Kodama T, Kraal G, et al. Defective microarchitecture of the spleen marginal zone and impaired response to a thymus-independent type 2 antigen in mice lacking scavenger receptors MARCO and SR-A. J Immunol (2005) 175:8173-80. doi:10.4049/ jimmunol.175.12.8173

69. Backer R, Schwandt T, Greuter M, Oosting M, Jüngerkes F, Tüting T, et al. Effective collaboration between marginal metallophilic macrophages and $\mathrm{CD} 8^{+}$dendritic cells in the generation of cytotoxic T cells. Proc Natl Acad Sci U S A (2010) 107:216-21. doi:10.1073/pnas.0909541107

70. Kanayama M, Inoue M, Danzaki K, Hammer G, He YW, Shinohara ML. Autophagy enhances NFKB activity in specific tissue macrophages by sequestering A20 to boost antifungal immunity. Nat Commun (2015) 6:5779. doi:10.1038/ncomms6779

71. Gwyer Findlay E, Villegas-Mendez A, de Souza JB, Inkson CA, Shaw TN, Saris CJ, et al. IL-27 receptor signaling regulates CD4+ T cell chemotactic responses during infection. J Immunol (2013) 190:4553-61. doi:10.4049/ jimmunol.1202916

72. Ravishankar B, Shinde R, Liu H, Chaudhary K, Bradley J, Lemos HP, et al. Marginal zone CD169+ macrophages coordinate apoptotic cell-driven cellular recruitment and tolerance. Proc Natl Acad Sci U S A (2014) 111:4215-20. doi:10.1073/pnas.1320924111

73. Recalcati S, Locati M, Gammella E, Invernizzi P, Cairo G. Iron levels in polarized macrophages: regulation of immunity and autoimmunity. Autoimmun $\operatorname{Rev}(2012)$ 11:883-9. doi:10.1016/j.autrev.2012.03.003

74. Nolte MA, Arens R, Kraus M, van Oers MH, Kraal G, van Lier RA, et al. B cells are crucial for both development and maintenance of the splenic marginal zone. J Immunol (2004) 172:3620-7. doi:10.4049/jimmunol.172.6.3620

75. Engwerda CR, Ato M, Cotterell SE, Mynott TL, Tschannerl A, Gorak-Stolinska PM, et al. A role for tumor necrosis factor-alpha in remodeling the splenic marginal zone during Leishmania donovani infection. Am J Pathol (2002) 161:429-37. doi:10.1016/S0002-9440(10)64199-5

76. Mackay F, Majeau GR, Lawton P, Hochman PS, Browning JL. Lymphotoxin but not tumor necrosis factor functions to maintain splenic architecture and humoral responsiveness in adult mice. Eur J Immunol (1997) 27:2033-42. doi:10.1002/eji.1830270830

Conflict of Interest Statement: The authors declare that the research was conducted in the absence of any commercial or financial relationships that could be construed as a potential conflict of interest.

Copyright ( 2015 Borges da Silva, Fonseca, Pereira, Cassado, Álvarez and D'Império Lima. This is an open-access article distributed under the terms of the Creative Commons Attribution License (CC BY). The use, distribution or reproduction in other forums is permitted, provided the original author(s) or licensor are credited and that the original publication in this journal is cited, in accordance with accepted academic practice. No use, distribution or reproduction is permitted which does not comply with these terms. 